\section{Research Square}

\title{
Analysing the performance of health systems in Asian countries: What Myanmar can learn from Bangladesh and Vietnam
}

\author{
Curt Löfgren ( $\nabla$ curt.lofgren@umu.se ) \\ Umea Universitet Medicinska fakulteten https://orcid.org/0000-0002-5348-7698 \\ Zin Mar Win \\ Umea Universitet Medicinska fakulteten
}

\section{Research article}

Keywords: data envelopment analysis, health care cost, efficiency, Myanmar, Asian countries

Posted Date: April 10th, 2020

DOI: https://doi.org/10.21203/rs.3.rs-21181/v1

License: (c) (i) This work is licensed under a Creative Commons Attribution 4.0 International License. Read Full License 


\section{Abstract}

Background

Advancements in medicine leads, among other things, to increasing life expectancy. However, at the same time, health care costs are increasing, and this may not be sustainable in the future. Governments and health care organizations need to implement efficiency measures in order to maximize health outcomes within available resources. This study aims to compare the technical efficiency of health systems in Asian countries, and to identify "efficient peers" for each "inefficient country": in particular, for Myanmar.

Methods

A DEA variable returns to scale output-oriented model was used to evaluate technical efficiency in thirteen Asian countries. The input variables were current health expenditure per capita, the density of doctors, and the density of nurses and midwifery personnel. Two output variables, health adjusted life expectancy (HALE) and the infant mortality rate were (IMR) analysed separately. Myanmar may learn how to improve efficiency of its health care system through studying its efficient peers from DEA results. A review of relevant English language literature was used as a basis for informing a comparative analysis of the health systems of Myanmar and its efficient peers, Bangladesh and Vietnam.

Results

Among the thirteen Asian countries studied, $38.5 \%$ and $53.8 \%$ of countries were technically efficient when HALE and IMR were used as the measured output respectively. More countries were efficient at reducing IMR than increasing HALE. Myanmar is one of the most inefficient countries, and it should look at the health systems of its efficient peers, Bangladesh and Vietnam, to make its health system technically more efficient.

Conclusions

The results of this study suggested that countries with inefficient health systems can improve their health outcomes without increasing their health care resources. As DEA measures efficiency only, future studies should take into account equity to assess comprehensive health system performance.

\section{Background}

Advancements in medicine help people live longer. Life expectancy is increasing. According to data published by World Health Organization (WHO), life expectancy increased by 5.5 years between 2000 and 2016 globally (1). However, at the same time, health care is becoming more expensive. Between 2000 and 2016 , health expenditure per capita rose from US\$ 15 to 33 in low-income countries, from US\$22 to 79 in lower middle- income countries, from US\$ 103 to 455 in upper middle-income countries, and from US\$2430 to 5180 in high-income countries (2). As such, increasing health care costs is a major challenge for almost every country in the world. 
The significant amounts of health care spending are wasted worldwide. The WHO estimates that globally $20 \%-40 \%$ of total health spending, equivalent to a current monetary value around 1.5 trillion, is being wasted every year due to health system inefficiency (5). Inefficient health systems negatively impact on population health, which in turn affects productivity, education, and human welfare $(3,4)$. According to 2010 estimates from the Organization for Economic Cooperation and Development (OECD), life expectancy at birth would increase by more than two years without increasing health care spending, if the health care systems of all OECD countries performed at their maximum levels (6). These issues highlight the need for greater efficiency in health system.

In general, countries that spend more on health have higher life expectancies (7). For example, an average life expectancy at birth for high-income countries was 80.6 years whereas 62.9 years for low-income countries in 2016 (8). However, countries that spend most on their health care do not necessarily have best health outcomes, best exemplified by the United States (7). Interestingly, countries with differing proportions of health care expenditure can have similar health outcomes. For instance, life expectancy in Uruguay and that in Paraguay are the same (75 year), but Uruguay's health expenditure per capita is four times higher than Paraguay's $(6,9,10)$. Even though there are other determinants of health, there clearly is scope to improve the effectiveness of health care spending within countries (6).

Efficiency in the health sector means achieving maximum health within available resources or using minimum resources for the given level of outputs. This is "technical efficiency" in economic terms $(5,11)$. Health care efficiency can be measured at micro level to compare performance in diagnostic and therapeutic procedures between departments and hospitals etc., $(11,12)$ at meso-level to evaluate organizational efficiency $(13)$, and at macro level to assess health systems between countries $(3,14,15)$. Cross- country comparisons of health system performance can provide opportunities to identify whether countries' health systems are performing efficiently, and to take appropriate actions to improve efficiencies in under-performing countries (16).

In terms of health care spending, Asian countries spend much less than OECD countries. Current health expenditure (CHE), expressed as percentage of gross domestic product (GDP), for East Asia and the Pacific Region was 6.6\% and that in the South Asia Region was 3.6\% in 2016. In contrast, 2016 CHE for OECD countries was $12.6 \%$ (17). In addition, out-of-pocket payments (OOPs) as a percentage of CHE are very high in some Asian countries; OOPs were more than 70\% of CHE in Myanmar and Bangladesh in 2016 (18). High OOPs are strongly correlated with catastrophic health expenditure and impoverishment and can exacerbate poverty $(19,20)$. Moreover, South East Asian region countries are now facing a triple burden of diseases: communicable diseases, non-communicable diseases, and injuries (21). All these factors demand efficient use of health care resources, especially in resource limited Asian countries, in order to improve health of their populations.

Some previous studies have analysed health system efficiency in OECD countries $(3,14,22)$, but few have compared health system efficiency in Asian countries (15). To our knowledge, no studies have as yet undertaken comparative analysis of the health systems of inefficient Asian countries with the purpose of benchmarking so that inefficient countries might adopt best practices with regard to improving efficiency. 
This study includes ten members of the Association of Southeast Asian Nations (ASEAN) (Brunei, Cambodia, Indonesia, Laos, Malaysia, Myanmar, the Philippines, Singapore, Thailand, and Vietnam) together with three neighbouring countries of Myanmar (Bangladesh, China, and India). The aim is to compare the technical efficiency of health systems in Asian countries and to identify "efficient peers" for each of the "inefficient" countries.

\section{Methods}

\section{Data Envelopment Analysis (DEA)}

DEA is one of the most widely used methods to measure the technical efficiency of operating units (called decision making units, DMU). It is a non-parametric, linear programming technique that measures the relative technical efficiency of several decision-making units by calculating the ratio of the weighted sum of outputs to the weighted sum of inputs. The efficiency frontier is plotted based on the combinations of inputs and outputs of the best performing DMUs and the efficiency of each other unit can be measured by comparing it with an identified frontier of efficiency. The efficiency ratio ranges from zero to one, with the efficiency frontier being scored 1 (100\%) and the inefficient units falling below the frontier scored less than $1(0-99 \%)$. DMUs located on the frontier are known as "benchmarks or peers". These are the best practice examples which allow comparison with less efficient DMUs. DEA is also considered as a powerful benchmarking technique (23).

The DEA method was originally introduced by Charnes, Cooper, and Rhodes in 1978 assuming constant returns to scale. It should be used when all DMUs are operating at an optimal scale. In 1984, Banker, Charnes, and Cooper developed a second DEA model assuming variable returns to scale. This is appropriate when DMUs are not operating at an optimal scale, i.e. DMUs facing imperfect competition, government regulations, etc. Increasing returns to scale (or economies of scale) is a situation where changes in input of $1 \%$ results in greater than $1 \%$ changes in output. Conversely, decreasing returns to scale (or diseconomies of scale) refers to a situation where changes in input of $1 \%$ results in less than $1 \%$ changes in output. The DEA model can be input or output oriented. An output-oriented DEA model maximizes output for a given level of input, whereas, an input-oriented DEA minimizes input for a given level of output (23).

This study uses variable returns to scale, an output-oriented model. Variable returns to scale are used because the health care systems in the studied Asian countries (DMUs) differ in terms of per capita incomes, health financing policies and socio-economic characteristics. An output-oriented model is used as most of the health system objectives refer to maximizing health outcomes by using available resources as efficient as possible. Moreover, inputs such as health expenditure and health care professionals are already assigned, so that it would be inappropriate to advise to reduce health care inputs by using an input-oriented model.

\section{Data and Variables}

Data were collected for the year 2016 from WHO Global Health Expenditure Database and WHO Global Health Observatory Data Repository (24-28). Where 2016 data were not available, the closest earlier data 
were used. WHO data are comparable across countries which is crucial for DEA. The WHO uses the System of Health Accounts (SHA 2011) framework to provide comparable national health expenditure statistics internationally $(29,30)$.

For the analysis, it is important that the selected health resource inputs have significant impact on the selected outputs. Three selected input variables are current health expenditure per capita in international dollars (Int\$), density of doctors, and density of nursing and midwifery personnel for thirteen Asian countries $(18,26,27)$. The output variables, HALE and IMR were used in analysis 1 and 2 respectively $(25$, 31). The IMR was converted to the infant survival rate (ISR) for consistency with the DEA assumption that more output is better. The ISR is 1-IMR/1000 (32). The selection of three inputs and one output meets the DEA model requirement in that the number of decision- making units or countries $(n=13)$ exceeds three times the number of input and output variables (23). 
Table 1

Input and output variables of thirteen Asian countries

\begin{tabular}{|c|c|c|c|c|c|c|c|}
\hline & Countries & $\begin{array}{l}\text { CHE per } \\
\text { capita in } \\
\text { international } \\
\text { dollar }\end{array}$ & $\begin{array}{l}\text { Doctors } \\
\text { per } 10,000 \\
\text { population }\end{array}$ & $\begin{array}{l}\text { Nursing and } \\
\text { midwifery } \\
\text { personnel per } \\
10,000 \\
\text { population }\end{array}$ & $\begin{array}{l}\text { Health } \\
\text { adjusted } \\
\text { life } \\
\text { years }\end{array}$ & $\begin{array}{l}\text { IMR } \\
\text { per } \\
1000 \\
\text { live } \\
\text { births }\end{array}$ & $\begin{array}{l}\text { ISR = 1- } \\
\text { IMR/1000 }\end{array}$ \\
\hline 1 & Bangladesh & 89.00 & 4.82 & 2.56 & 63.30 & 28.00 & 0.972 \\
\hline 2 & Brunei & 1975.00 & 17.70 & 66.01 & 67.90 & 9.40 & 0.9906 \\
\hline 3 & Cambodia & 229.00 & 1.68 & 9.55 & 60.80 & 26.20 & 0.9738 \\
\hline 4 & China & 763.00 & 17.86 & 23.07 & 68.70 & 8.50 & 0.9915 \\
\hline 5 & India & 233.00 & 7.59 & 20.98 & 59.30 & 33.20 & 0.9668 \\
\hline 6 & Indonesia & 363.00 & 2.74 & 13.00 & 61.70 & 22.60 & 0.9774 \\
\hline 7 & Laos & 155.00 & 5.00 & 9.76 & 57.90 & 40.40 & 0.9596 \\
\hline 8 & Malaysia & 1054.00 & 15.13 & 40.72 & 66.60 & 6.80 & 0.9932 \\
\hline 9 & Myanmar & 273.00 & 6.21 & 10.38 & 58.40 & 39.30 & 0.9607 \\
\hline 10 & Philippines & 344.00 & 12.75 & 33.35 & 61.70 & 23.40 & 0.9766 \\
\hline 11 & Singapore & 4021.00 & 23.06 & 72.14 & 76.20 & 2.20 & 0.9978 \\
\hline 12 & Thailand & 639.00 & 4.46 & 27.79 & 66.80 & 8.60 & 0.9914 \\
\hline \multirow[t]{4}{*}{13} & Vietnam & 357.00 & 8.20 & 14.32 & 67.50 & 17.20 & 0.9828 \\
\hline & Mean & 807.31 & 9.78 & 26.43 & 64.37 & 20.45 & 0.9796 \\
\hline & Minimum & 89.00 & 1.68 & 2.56 & 57.90 & 2.20 & 0.9596 \\
\hline & Maximum & 4021.00 & 23.06 & 72.14 & 76.20 & 40.40 & 0.9978 \\
\hline
\end{tabular}

\section{Statistical Analysis}

STATA 16.0 was used to perform the DEA. The data set included input and output variables for selected Asian countries. First, the countries were named "dmu"- decision making units. The DEA program was run by entering input and output variables. For the analysis reported in this paper, variable returns to scalerts(vrs) and output-oriented model-ort(out)- options were chosen.

\section{Comparative Analysis}

Information on the health systems in Myanmar and its benchmark countries, Bangladesh and Vietnam, was extracted from the published scientific literature in online databases, PubMed and Google Scholar etc. 
Search terms are "health system in Bangladesh", "health system in Myanmar", "health system in Vietnam" and "health system changes in Asia".

\section{Results}

DEA Results

The descriptive statistics of the input and output variables for thirteen Asian countries are shown in Table 1. Bangladesh has the minimum value of CHE per capita (Int\$89.00) and nursing and midwifery personnel (2.56), whereas, the lowest number of doctors (1.68) is found in Cambodia. The HALE (57.9) and ISR (0.9596) are the lowest in Laos. Singapore has the highest value for all variables.

The selected countries in this study have similar geographical backgrounds, however, their economic circumstances vary with GDP per capita in 2016 ranging from Int\$3835 to Int\$90917 (18). According to the World Bank income classification for 2019 fiscal year, Brunei and Singapore are high-income countries, China, Malaysia and Thailand are upper-middle-income countries and the rest are lower-middle-income countries (33). 
Table 2

Variable returns to scale, output-oriented DEA results

\begin{tabular}{|c|c|c|c|c|c|c|c|c|c|}
\hline & \multirow{3}{*}{ DMUs } & \multicolumn{4}{|c|}{ Analysis 1} & \multicolumn{4}{|c|}{ Analysis 2} \\
\hline & & \multicolumn{4}{|l|}{ HALE } & \multicolumn{4}{|c|}{ IMR/ISR } \\
\hline & & Rank & $\begin{array}{l}\text { VRS } \\
\text { TE }\end{array}$ & RTS & $\begin{array}{l}\% \\
\text { improvement } \\
\text { in output }\end{array}$ & Rank & $\begin{array}{l}\text { VRS } \\
\text { TE }\end{array}$ & RTS & $\begin{array}{l}\% \\
\text { improvement } \\
\text { in output }\end{array}$ \\
\hline 1 & Bangladesh & 1 & 1 & 0 & 0 & 1 & 1 & 0 & 0 \\
\hline 2 & Brunei & 9 & 0.9506 & -1 & 4.9398 & 9 & 0.9960 & -1 & 0.405 \\
\hline 3 & Cambodia & 1 & 1 & 0 & 0 & 1 & 1 & 0 & 0 \\
\hline 4 & China & 1 & 1 & -1 & 0 & 1 & 1 & -1 & 0 \\
\hline 5 & India & 12 & 0.9046 & 1 & 9.5440 & 11 & 0.9887 & 1 & 1.1253 \\
\hline 6 & Indonesia & 7 & 0.9865 & -1 & 1.3497 & 8 & 0.9996 & -1 & 0.0367 \\
\hline 7 & Laos & 11 & 0.9065 & 1 & 9.3521 & 12 & 0.9848 & 1 & 1.5200 \\
\hline 8 & Malaysia & 8 & 0.9614 & -1 & 3.8627 & 1 & 1 & -1 & 0 \\
\hline 9 & Myanmar & 13 & 0.8920 & 1 & 10.8044 & 13 & 0.9816 & 1 & 1.8447 \\
\hline 10 & Philippines & 10 & 0.9168 & 1 & 8.3159 & 10 & 0.9942 & -1 & 0.5779 \\
\hline 11 & Singapore & 1 & 1 & -1 & 0 & 1 & 1 & -1 & 0 \\
\hline 12 & Thailand & 6 & 1 & -1 & 0 & 1 & 1 & -1 & 0 \\
\hline \multirow[t]{2}{*}{13} & Vietnam & 1 & 1 & -1 & 0 & 1 & 1 & -1 & 0 \\
\hline & Mean & & 0.9629 & & 6.8812 & & 0.9958 & & 0.9183 \\
\hline
\end{tabular}

Table 2 illustrates the DEA results. For analysis (1) in which HALE is the output of interest, five out of thirteen countries - Bangladesh, Cambodia, China, Singapore and Vietnam- demonstrated pure technical efficiency. Myanmar was the least efficient country with VRS efficiency score of 0.8920 , meaning that Myanmar could increase output (HALE) by $10.80 \%$ with existing inputs. The VRS efficiency scores for the other non-efficient countries varied from 0.9046 to 0.9865 , which means that these countries could increase HALE by between 1.35-9.54\% without increasing inputs. India, Laos, Myanmar and the Philippines were facing increasing returns scale, whereas, the remaining inefficient countries experienced decreasing returns to scale.

For analysis 2, the ISR was the output. Seven out of thirteen countries -Bangladesh, Cambodia, China, Malaysia, Singapore, Thailand and Vietnam- were technically efficient. Myanmar (VRS efficiency score 
0.9816) was the least efficient country and could improve its health outcome performance by $1.84 \%$ at current input levels if they perform at maximum efficiency. For the other inefficient countries, VRS efficiency levels ranged between 0.9848 and 0.9996 , indicating that $0.04-1.52 \%$ of increased output can be achieved without using more inputs. India, Laos and Myanmar were facing increasing returns to scale, while the other inefficient countries faced decreasing returns to scale.

Table 3

Inefficient countries and their peers with reference weight

\begin{tabular}{|llll|}
\hline & DMUs & Composite countries for HALE & Composite countries for ISR \\
\hline 1 & Bangladesh & - & - \\
\hline 2 & Brunei & $4(0.35), 11(0.38), 13(0.22)$ & $8(0.69), 11(0.31)$ \\
\hline 3 & Cambodia & - & - \\
\hline 4 & China & - & - \\
\hline 5 & India & $1(0.42), 13(0.49)$ & $1(0.46), 13(0.53)$ \\
\hline 6 & Indonesia & $1(0.32), 3(0.68)$ & $1(0.13), 3(0.64), 12(0.24)$ \\
\hline 7 & Laos & $1(0.78), 13(0.12)$ & $1(0.84), 12(0.09), 13(0.06)$ \\
\hline 8 & Malaysia & $4(0.49), 11(0.13), 13(0.34)$ & - \\
\hline 9 & Myanmar & $1(0.43), 13(0.46)$ & $1(0.46), 12(0.11), 13(0.42)$ \\
\hline 10 & Philippines & $1(0.04), 13(0.87)$ & $1(0.05), 13(0.95)$ \\
\hline 11 & Singapore & - & - \\
\hline 12 & Thailand & $1(0.85), 3(0.21)$ & - \\
\hline 13 & Vietnam & - & - \\
\hline $\begin{array}{l}\text { DMUs }=\text { decision making units, HALE = health adjusted life expectancy, ISR = infant survival rate, } \\
\text { Reference weight = weight given to each peer according to its importance among peer group, composite } \\
\text { countries = a group of comparable, closest efficient peers }\end{array}$ & \\
\hline
\end{tabular}

Table 3 shows inefficient countries and their peers (composite members) with reference weight given. For each inefficient DMU, the DEA identifies the comparable, closest efficient DMU peers as the best practice examples to improve the performance of inefficient DMUs (12). Reference weight given to each peer corresponds to its relative importance for each peer among composite members. For example, Myanmar's composite countries for HALE is formed by Bangladesh (weight 0.43) and Vietnam (0.46), and for ISR is composed by Bangladesh (0.46), Vietnam (0.42) and Thailand (0.11). The country should look at best practice of peers associated with the highest weight value so that the role models for Myanmar will be Bangladesh and Vietnam for improvement in both HALE and ISR.

Comparative analysis of health systems of Myanmar, Bangladesh and Vietnam 
Myanmar should learn successful strategies of health systems from its benchmark countries, Bangladesh and Vietnam, to improve efficiency. "A system framework for analysing the efficiency of health care resource use" indicates that health system efficiency can be influenced by a set of policy instruments: financing, provider payment methods, organization and regulation (10). The policy makers should target these instruments to reform their health system to be more efficient. In the following sections, the health systems of three countries are compared and analysed in terms of policy instruments. However, provider payment methods are not used owing to a lack of comparable data.

\section{Financing}

Table 4

Health care financing in Myanmar, Bangladesh and Vietnam

\begin{tabular}{|llll|}
\hline & Myanmar & Bangladesh & Vietnam \\
\hline CHE as \% of GDP & $5 \%$ & $2 \%$ & $6 \%$ \\
\hline Government health expenditure as \% of CHE & $14 \%$ & $16 \%$ & $47 \%$ \\
\hline OOPs as \% of CHE & $77 \%$ & $73 \%$ & $45 \%$ \\
\hline Other private health expenditure as \% of CHE & & $3 \%$ & $6 \%$ \\
\hline External health expenditure as \% of CHE & $9 \%$ & $8 \%$ & $2 \%$ \\
\hline Voluntary health insurance as \% of CHE & & & $1 \%$ \\
\hline Government health expenditure in Int\$ & 38 & 15 & 169 \\
\hline OOPs in Int\$ & 210 & 65 & 159 \\
\hline
\end{tabular}

$\mathrm{CHE}=$ current health expenditure, GDP = gross domestic product, OOPs = out of pocket payment, Int\$= international dollars

Table 4. describes health financing of Myanmar, Bangladesh and Vietnam. Myanmar's current health expenditure is around $5 \%$ of gross domestic product (GDP). The majority of $\mathrm{CHE}$ comes from OOPs $(77 \%)$ and domestic general government health expenditure is only $14 \%$ (18). Health insurance scheme called 'Social Security Scheme (SSS)" for employees is regulated through the Ministry of Labour but its contribution is negligible (34).

In Bangladesh, current health expenditure is only $2 \%$ of GDP. CHE is mainly made up of OOPs (73\%) and only $16 \%$ are contributed by domestic general government health expenditure (18). In recent years, some NGOs have piloted health insurance schemes, however, there is no successful health insurance in Bangladesh yet (35).

The CHE of Vietnam is around 6\% of GDP. Government health expenditure is the highest among three countries (47\% of CHE) and OOPs is only 45\% (18). Vietnam's Health insurance was first introduced in 1993, 
starting for formal public and non- public sectors to protect people from financial risk. In 2015 , health insurance coverage reached $77 \%$ of populations $(36,37)$.

\section{Organization}

Myanmar's health care system has evolved with changing political situation and growing demand from people. Although both public and private sectors are involved in health care financing and provision, the Ministry of Health $(\mathrm{MOH})$ remains the major provider of comprehensive health care services providing all aspects of health care. The $\mathrm{MOH}$ supervises both administrative and technical functions of state/region health departments, district health departments and township health departments (38). The private, for profit, sector has expanded rapidly especially in major cities and it is estimated to provide $75 \%-80 \%$ of ambulatory care (34).

International aid agencies used to have difficulty in engaging Myanmar Government under the isolated military regime, but this is changing under the quasi-civilian government (39). At present, community-based organizations, local and international non-governmental organizations are increasingly involved to deliver health care services across the country. However, one review article about 'Healthcare in Myanmar' suggests donors to discuss the health care systems more openly to reduce overlapping functions and to avoid duplicated donations (34).

The Bangladesh health system is made up of five-layers. The lowest level is village health facility with community clinics, the second layer is Union health and Family Welfare Centre, the next level is the Upazila Health Complex and the fourth level is the district hospital with theatre facilities. Medical colleges and postgraduate institutes offering a wide range of health services are at the top of the health system (40).

The government of Bangladesh accommodates many stakeholders and explicitly works together with the private sectors, local and international non-governmental organizations (NGOs) and informal providers. Extensive community programs are very successful in reaching all households in community and implementing health programs such as maternal and child health and family planning programs etc. Prowomen development programs in education, economy as well as health sectors shown to improve health of the population (41).

Vietnam's health care system comprises a mix of public and private sectors. Private hospitals which are a major part of the health care system are delivering more than $60 \%$ of outpatient services. The health system is divided into four administrative levels. Central level includes central hospitals owned by Ministry of Health and city hospitals managed by city municipalities. Provincial level, district level and commune level are administered by local provincial government and are covering a population of 1-2 million, 100,000200,000 and approximately 5,000-10,000 respectively (37).

\section{Regulation}

In terms of regulations and policy, Myanmar has regulations for licensing medical professionals, the national essential medicine policy, the food and drug administration regulations and national health plan every five years but there are few resources and limited capacity to implement them (42). 
The government of Bangladesh has established professional regulatory and statutory bodies such as the Bangladesh Medical and Dental Council and Pharmacy council, etc. The National Drug Policy was updated in 2016 to ensure the access to the essential medicines. The Health Care Financing Strategy 2012-2032 was developed aiming to increase funding to reduce personal expenditure on healthcare services and to protect financial risk (40).

Vietnam's Ministry of Health is responsible for setting rules and regulations in health system and carried out health care provision under direction of health care activities (DOHA) (37). In 2014, the Health Insurance Law was revised, aiming to cover $100 \%$ of population with health insurance. The Pharmaceutical Law was revised in 2015 ensuring access to affordable quality essential medicines (43).

\section{Discussion}

\section{Discussions of DEA results, strengths and weakness}

Out of thirteen countries, five (38.5\%) were technically efficient for the output HALE, while seven $(53.8 \%)$ were technically efficient for the output IMR. The inefficient countries could improve HALE and IMR by $6.88 \%$ and $0.92 \%$ respectively (compared to efficient countries in this study) without using more resources. The findings suggest that more countries are efficient in reducing IMR than increasing HALE so that inefficient countries have more room for improvement with regard to HALE rather than IMR.

The findings from a previous study of OECD countries were mixed (14). Similar to this study, more countries were efficient for IMR; 19 (70.4\%) out of 27 countries were efficient for IMR whereas 13 (48.1\%) were efficient for life expectancy (LE). However, inefficient OECD countries on average could increase their LE by only $2.1 \%$ but could reduce IMR by $14.5 \%$ with existing resources so that inefficient countries had more room for improvement in IMR than in HALE. A possible reason why Asian countries are more efficient at reducing IMR is that there may be more policy emphasis on maternal and child health given that the IMR was one of the important targets under the Millennium Development Goals and is a current target under the Sustainable Development Goals $(44,45)$.

The DEA's identification of peers provides an important and useful policy information for inefficient countries to reform their health systems. The selected sample in this paper included Asian countries only. Geographic proximity makes it easier for country to relate within their region. As HALE and IMR were analyzed separately, an inefficient country could focus more on peer countries with higher reference weights, depending upon the area of improvement that is being targeted.

Although DEA is very useful, it has its own limitations. The method cannot measure true efficiency and results can change depending on the number and nature of DMUs selected in the sample. The inefficiency results tend to be underestimated as it is calculated in relation to the efficiency frontier of the sample. For instance, Myanmar's efficiency score 0.8920 (for HALE) does not mean that it could improve only by $10.80 \%$. It means that Myanmar could improve $10.80 \%$ compared to the most efficient country in the sample selected. 
In this analysis, only CHE per capita, doctor density and nursing and midwifery personnel density were used as inputs. Although other factors outside of health system like education, social class, lifestyle, environmental factors and country policy etc. play an important role in health outcomes, these factors were not taken into account in this study.

\section{What Myanmar can learn from Bangladesh and Vietnam From Bangladesh}

Bangladesh has been recognized as an example of "good health at low cost" and praised for exceptional health achievements (46).

First thing that Myanmar should learn from Bangladesh is its extensive community-based health service delivery system. It reached almost all the households in rural areas and achieved high coverage. For decades, both government and NGOs use large-scale community-based health workers to address the shortage of human resources in health sectors. One successful TB community program (more than $90 \%$ cure rate) was already adopted by South Africa for treatment of TB and HIV (47).

Another thing to learn is Bangladesh government's willingness to create an environment for pluralistic health system. Government of Bangladesh has partnered with NGOs, private sectors, informal providers and international donors etc., to address limitation of health care resources in government in order to improve health outcomes of population (47).

Last but not the least, Myanmar should look at how women empowerment in education, economic as well as in health sectors make impressive achievement in Bangladesh's health system. Bangladesh's education policy that favours girls reduced gender inequality and helped achieve almost universal primary education for aged 6-10 years. Grameen's microcredit for poor rural population, especially for women, was well known innovation in economy and was awarded Nobel Peace Prize in 2006 (41). This microcredit program, together with improvement in education, helped increase women empowerment. This, in turn, has positive effect on women decision making power within and beyond their own family including decision making for health of their family members. In health sector itself, women are employed as frontline workers for most community-based programs, and have exceptional achievements (48).

\section{From Vietnam}

One important thing Myanmar can learn from Vietnam is about health insurance. In 1993, health insurance law passed and launched national health insurance program with contributions from health workers. To expand health coverage for the poor, disadvantaged and ethnic minorities, a Health Care Fund for the Poor (HCFP) was created. It was merged with national contributory scheme and this merger reduced the fragmentation in health system. The national health program includes a contributory program for the formally employed, civil servants and pensioners and non-contributory program for the poor, disadvantaged population and ethnic minorities. Non-contributory program is subsidized by the government revenue mainly from value added tax (VAT) and other local taxes (36). In 2014, the Health Insurance Law was 
revised aiming to cover entire population with health insurance (43). Health insurance coverage had reached $77 \%$ of population in 2015 (37).

Myanmar health care system is still weak in above mentioned practices; therefore, it will be very useful for Myanmar to adopt these approaches in order to reform its health system. These examples show how nonhealth approaches such as economic development, education and women's empowerment as well as health system related strategies such as health insurance system, large-scale community-based programs, creating an environment for donors play very important role in health system improvement.

\section{Concluding Remarks}

Health system efficiency is crucial to improve health outcomes of populations especially in the current situation of increasing health care costs resulting from aging populations and expensive medical care. Knowing the efficiency of a country's health system provides the opportunity to analyse health systems and to take appropriate actions to improve performance. Our cross-country comparison of health system performance by using DEA provides empirical evidence of the technical efficiency of health systems in thirteen Asian countries. The findings suggest that countries with inefficient health systems can improve their health outcomes without increasing health care resources. Results also highlight that more countries in this group are performing better with regard to reducing IMR rather than increasing HALE. Moreover, DEA identifies most comparable benchmark countries for every inefficient country so that inefficient countries can potentially emulate policies and practices of their efficient peers. It will be very beneficial for Myanmar to learn useful practical approaches and policies of its peers, Bangladesh and Vietnam, from our comparative analysis of health systems of these countries.

However, efficiency alone is not enough to meet the needs of increasing demand especially in resourceconstrained countries. The amount of resources governments spend on health care is also important to provide basic health care that their citizens need. One paper argues that government health expenditure should be more than $5 \%$ of GDP and more than US\$86 per capita in the pursuit of universal health coverage (49). In addition, DEA cannot measure equity of health care. According to the economic theory, a situation where there is pareto efficiency; allocation of resources in which no individual can be made better off without making another individual worse off; there may be no equity (10). Some studies suggest that instead of health gain and health equity as two separate outcomes, combination of these two should be the one combined goal of the health system that we should try to achieve as efficient as possible (50). Another suggestion that is based on the phenomenon called relative income hypothesis is that income inequality is inversely related to health outcomes, meaning that individual living in a more equal income society will have better health status (51). Therefore, targeting at reducing income inequality together with improving health outcomes of a society efficiently will be a way to achieve both efficiency and equity. Future research should be aimed at developing methodologies to measure efficiency and equity together to assess the comprehensive health system performance.

\section{Abbreviations}


AIDS: Acquired Immune Deficiency Syndrome; ASEAN: The Association of Southeast Asian Nations; CHE: Current Health Expenditure; DEA: Data Envelopment Analysis; DMU: Decision Making Units; GDP: Gross Domestic Product; GNI: Gross National Income; HALE: Health Adjusted Life Expectancy; HIV: Human Immunodeficiency Virus; IMR: Infant Mortality Rate, INGO: International Non-Governmental Organization; Int\$: International Dollars; ISR: Infant Survival Rate; LE: Life Expectancy; MMR: Maternal Mortality Rate; NGO: Non-Governmental Organization; OECD: Organization for Economic CO-operation and Development; OOPs: Out of Pocket Payments; VAT: Value Added Tax; WHO: World Health Organization.

\section{Declarations}

\section{Ethics approval and consent to participate}

Not applicable

\section{Consent for publication}

Not applicable

\section{Availability of data and materials}

The datasets used and analyzed during the current study are publicly available from World Health Organization (WHO) and World Bank.

\section{Competing Interest}

The authors declare that they have no competing interests.

\section{Funding}

This study was unfunded.

\section{Authors' contributions}

ZMW analyzed the data and drafted the manuscript. CL reviewed the manuscript, provided feedback and approved the final submission.

\section{Acknowledgements}

The authors gratefully acknowledge the Department of Epidemiology and Global Health, Umea University where this study has been conducted. Thanks also to Jennifer Stewart Williams for reviewing and providing comments on the draft version of the manuscript.

\section{References}

1. WHO | Life expectancy [Internet]. Geneva: World Health Organization; [cited 2019 Jul 8]. Available from: 
2. Current health expenditure. per capita (current US) | Data [Internet]. Washington DC: World Bank; [cited 2019 Apr 9]. Available from: .

3. Asandului L, Roman M, Fatulescu P. The Efficiency of Healthcare Systems in Europe: A Data Envelopment Analysis Approach. Procedia Econ Finance. 2014 Jan;1:10:261-8.

4. Growth_Commission_Working_Paper_24_Population_Health_Economic_Growth.pdf [Internet]. [cited 2019 Aug 18]. Available from: .

5. Chisholm D, Evans D. Improving health system efficiency as a means of moving towards universal coverage. Geneva: World Health Organization; 2010. p. 34. Report No : World Health Report.

6. OECD. 2010, "Health care systems: Getting more value for money." Paris: Organization for Economic Cooperation and Development; 2010. Report No.: OECD Economics Department Policy Notes, No. 2.

7. Link between health spending and life expectancy. US is an outlier [Internet]. Our World in Data. [cited 2019 Jul 10]. Available from: .

8. Life expectancy at. birth, total (years) | Data [Internet]. Washington DC: World Bank; [cited 2019 Aug 12]. Available from: .

9. OECD

OECD. Health at a Glance 2009: OECD Indicators [Internet]. OECD. 2009 [cited 2019 Jul 10]. (Health at a Glance). Available from: .

10. Yip W, Hafez R. Improving Health System Efficiency. Reforms for improving the efficiency of health systems: lessons from 10 country cases. Health Syst Gov Financ. 2015;35.

11. Nayar P, Ozcan YA. Data Envelopment Analysis Comparison of Hospital Efficiency and Quality. J Med Syst. 2008 Jun 1;32(3):193-9.

12. $10.1108 /$ S0276-897620140000017014

Malhotra R, Lehrman S, Malhotra DK. Benchmarking Managed Healthcare Companies. In: Lawrence KD, Kleinman G, editors. Applications of Management Science [Internet]. Emerald Group Publishing Limited; 2015 [cited 2019 Mar 29]. p. 203-22. Available from: .

13. Hernández AR, Sebastián MS. Assessing the technical efficiency of health posts in rural Guatemala: a data envelopment analysis. Glob Health Action [Internet]. 2014 Jan 20 [cited 2019 Apr 13];7. Available from: .

14. Retzlaff-Roberts D, Chang CF, Rubin RM. Technical efficiency in the use of health care resources: a comparison of OECD countries. Health Policy. 2004 Jul;69(1):55-72.

15. Ahmed S, Hasan MZ, MacLennan M, Dorin F, Ahmed MW, Hasan MM, et al. Measuring the efficiency of health systems in Asia: a data envelopment analysis. BMJ Open. 2019 Mar 1;9(3):e022155.

16. Investing in health. benchmarking health systems [Internet]. The Nuffield Trust. 2017 [cited 2019 Apr 9 ]. Available from: .

17. Current health expenditure (\%. of GDP) | Data [Internet]. Washington DC: World Bank; [cited 2019 Apr 9]. Available from: .

18. GHO | By. category | Current health expenditure (CHE) - Data by country [Internet]. Geneva: World Health Organization (WHO). [cited 2019 Apr 3]. Available from: . 
19. WHO | Out-of-pocket payments, user fees and catastrophic expenditure [Internet]. Geneva: World Health Organization (WHO). [cited 2019 Jul 10]. Available from: .

20. van Doorslaer E, O'Donnell O, Rannan-Eliya RP, Somanathan A, Adhikari SR, Garg CC, et al. Effect of payments for health care on poverty estimates in 11 countries in Asia: an analysis of household survey data. Lancet Lond Engl. 2006 Oct;14(9544):1357-64. 368(.

21. Dhillon PK, Jeemon P, Arora NK, Mathur P, Maskey M, Sukirna RD, et al. Status of epidemiology in the WHO South-East Asia region: burden of disease, determinants of health and epidemiological research, workforce and training capacity. Int J Epidemiol. 2012 Jun;41(3):847-60.

22. Moreno-Enguix M, del R, Gómez-Gallego, Gallego JC. MG. Analysis and determination the efficiency of the European health systems. Int J Health Plann Manage. 2018;33(1):136-54.

23. Ishizaka A, Nemery P. Multi-Criteria Decision Analysis: Methods and Software [Internet]. New York, UNITED KINGDOM: John Wiley \& Sons, Incorporated; 2013 [cited 2019 Apr 23]. Available from: .

24. Global Health Expenditure Database [Internet]. [cited 2020 Feb 1]. Available from: .

25. GHO I By category. I Life expectancy and Healthy life expectancy - Data by country [Internet]. Geneva: World Health Organization (WHO). [cited 2019 Apr 8]. Available from: .

26. GHO |. By category | Medical doctors [Internet]. Geneva: World Health Organization (WHO). [cited 2019 Jun 17]. Available from: .

27. GHO | By category | Nursing and midwifery personnel [Internet]. Geneva: World Health Organization (WHO). [cited 2019 Apr 3]. Available from: .

28. GHO | By category. | Probability of dying per 1000 live births - Data by country [Internet]. Geneva: World Health Organization (WHO). [cited 2019 Oct 13]. Available from: .

29. WHO | Health Accounts [Internet]. WHO. [cited 2019 Dec 2]. Available from: .

30. Global Health Expenditure Database [Internet]. Geneva: World Health Organization (WHO). [cited 2019 Dec 3]. Available from: .

31. Mortality. rate, infant (per 1,000 live births) | Data [Internet]. Washington DC: World Bank; [cited 2019 Apr 23]. Available from: .

32. Hadad S, Hadad Y, Simon-Tuval T. Determinants of healthcare system's efficiency in OECD countries. Eur J Health Econ. 2013 Apr 1;14(2):253-65.

33. World Bank Country and Lending Groups - World Bank Data Help Desk [Internet]. Washington DC: World Bank; [cited 2019 May 1]. Available from: .

34. Latt NN, Myat Cho S, Htun NMM, Saw YM, Myint MNHA, Aoki F, et al. Healthcare in Myanmar. Nagoya J Med Sci. 2016 May;78(2):123-34.

35. Islam A, Biswas T. Health System in Bangladesh: Challenges and Opportunities. Am J Health Res. 2014 Jan;1:2:366.

36. Barroy H, Jarawan E, Bales S. Universal Health Coverage for Inclusive and Sustainable Development. Washington DC: World Bank; 2014. p. 13. (Health, Nutrition and Population Global Practice World Bank Group). 
37. Takashima K, Wada K, Tra TT, Smith DR. A review of Vietnam's healthcare reform through the Direction of Healthcare Activities (DOHA). Environ Health Prev Med [Internet]. 2017 [cited 2019 Apr 24];22. Available from: .

38. WHO Country Cooperation Strategy. Myanmar 2014-2018. Geneva: World Health Organization; (World Health Organization, Country Office for Myanmar).

39. Risso-Gill I, McKee M, Coker R, Piot P, Legido-Quigley H. Health system strengthening in Myanmar during political reforms: perspectives from international agencies. Health Policy Plan. 2014 Jul;29(4) (1):466-74.

40. WHO country cooperation strategy. Bangladesh 2014-2017. Geneva: World Health Organization; (World Health Organization, Country Office for Bangladesh).

41. Chowdhury AMR, Bhuiya A, Chowdhury ME, Rasheed S, Hussain Z, Chen LC. The Bangladesh paradox: exceptional health achievement despite economic poverty. The Lancet. 2013 Nov;382(9906):1734-45.

42. The Republic of the Union of Myanmar Health System Review. World Health Organization; 2015.

43. Country Cooperative Strategy. at a glance, Vietnam. Geneva: World Health Organization; 2015.

44. WHO | Millennium Development. Goals (MDGs) [Internet]. WHO. [cited 2019 Sep 3]. Available from: .

45. WHO I. Monitoring health for the SDGs [Internet]. WHO. [cited 2019 Sep 3]. Available from: .

46. Good Health at Low Cost': 25 years on. What makes a successful health system?: Dina Balabanova, Martin McKee, Anne Mills, editors London: London School of Hygiene \& Tropical Medicine. 2011. Reprod Health Matters. 2012 Jan;20(39):212-4.

47. Das P, Horton R. Bangladesh: innovating for health. The Lancet. 2013 Nov;382(9906):1681-2.

48. El Arifeen S, Christou A, Reichenbach L, Osman FA, Azad K, Islam KS, et al. Community-based approaches and partnerships: innovations in health-service delivery in Bangladesh. The Lancet. 2013 Dec;382(9909):2012-26.

49. Ottersen T, Evans DB, Mossialos E, Røttingen J-A. Global health financing towards 2030 and beyond. Health Econ Policy Law. 2017 Apr;12(2):105-11.

50. Reidpath DD, Olafsdottir AE, Pokhrel S, Allotey P. The fallacy of the equity-efficiency trade off: rethinking the efficient health system. BMC Public Health. 2012 Jun 22;12(Suppl 1):S3.

51. Kawachi I, Kennedy BP. Income inequality and health: pathways and mechanisms. Health Serv Res. 1999 Apr;34(1 Pt 2):215-27. 